\title{
Automation - Equipped Working Place of a Construction Firm Management Engineer
}

\author{
Tatyana Bobrova*, Vladimir Nikitin* \\ * The Siberian Automobile and Highway Institute , 5, Prospect Mira, Omsk , \\ 644080 , RUSSIA
}

\begin{abstract}
The Siberian Automobile and Highway Institute presents the results of research on development of the AUTOMATION -EQUIPPED WORKING PLACE OF A CONSTRUCTION ENGINEER (AEWPCE) program package for a personal computer. The complex consists of three main blocks: BLOCK $A$ is the scheduling on the imitation model basis; BLOCK B is the standard and resource provision; BLOCK $\mathrm{C}$ is the situation management of construction. Each block has sufficiently high software. BLOCK B is the core of the system. Besides of calculation of all types of resources for long-term and short-term planning the block provides the forming and estimating of engineering solution variants by the method of Functional-Cost Analysis. Hierarchical type of the resource standard base structural arrangement permits the compact form presentation of variety of engineering processes and solutions in construction. The AEWPCE system includes the fund of physical and technical effects, which permits analysing of already available engineering processes in construction and the development of new ones. The AEWPCE system is being developed.
\end{abstract}

\section{INTRODUCTION}

The data reported in this paper resulted from a research having been carried out at the Siberian Automobile and Highway Institute for several years . The research was on focused the improvement of computer - technologies based construction management system. Wide-spread adoption of personal computers in construction firm practice activities resulted in practical realization of separate specific theoretical theses as applied to labour organization of a construction engineer directly connected with the production management. A complex of models, algorithms and programs for solving roduction problems with the use of a computer is developed. It povides working out the solutions oriented toward the achievement of effective results of production activities.

The Automation- Equipped Working Place of a Construction Engineer (AEWPCE ) program package for a personal computer is an element of the automated constuction management system and plays the role of an electronic assistant of a modern management engineer. 
The proposed automated complex performs the following functions:

1. The decrease of labour intensity when doing routine work, the acceleration of calculations and the spreading of information basis while managing the construction.

2. The solution of optimization problems using modern economic and mathematical methods, the formation of variants and the grounded choise of effective engineering and management solutions.

\section{AEWPCE STRUCTURE AND FUNCTIONS}

A rather complicated structure of the hereinbefore mentioned electronic assistant results from the versatile character of construction engineer activities. Three main blocks can be relatively marked out in the proposed AEWPCE complex. Fig.1 shows the generalized AEWPCE scheme .

A E W P C E

\begin{tabular}{|l|l|l|l|}
\hline \multicolumn{1}{|c|}{ BLOCK A } & \multicolumn{1}{c|}{ BLOCK B } \\
\cline { 2 - 4 } $\begin{array}{l}\text { Scheduling on the } \\
\text { imitation } \\
\text { model basis }\end{array}$ & Resources & $\begin{array}{l}\text { Standard and } \\
\text { resource } \\
\text { provision } \\
\text { Volumes }\end{array}$ & $\begin{array}{l}\text { Resources } \\
\text { Development } \\
\text { and estimation } \\
\text { of engineering } \\
\text { solution variants }\end{array}$ \\
\cline { 2 - 4 } & $\begin{array}{l}\text { Sitution } \\
\text { management } \\
\text { of work } \\
\text { production } \\
\text { Fund of physical } \\
\text { and technical } \\
\text { effects }\end{array}$ \\
\hline
\end{tabular}

Figure 1 The scheme of relationship between the AEWPCE main blocks

The details of each block are reported hereinafter.

BLOCK A. The software of this block includes the following:

1. Modelling and calculation of schedules and optimization connected with the duration of construction of linear-extended projects. The models take into account technological characteristics of construction in different climatic conditions, uneveness of work volume distribution and other factors. The imitation modelling algorithms realized in this program have been discussed in details [1]. 
2. Modelling, calculation and optimization connected with the terms prescribed for construction and the sequence of construction when erecting multi-project complexes. Matrix methods of cyclogram calculation were used. These methods provided for uninterrupted usage of resources and fields of operations have been discussed in details [2].

3. Formation of a construction firm annual program with the month breakdown, being optimal according to the rhythm criterion of using labour resources and machinery.

BLOCK B This block is the core of the system as it closely interacts with all problems connected with the resource provision being solved in the AEWPCE program package. The RESURS computing complex is the central program of this block.

The hierarchical structure of the standard base is the main characteristic of the resource calculation method realized in this program. It consits of a number of enclosed menus having a set of positions successively revealing the definite features of engineering processes. The scheme of the RESURS program standard base is shown as a "TREE" type graph (Fig.2). The principle of the scheme drawing results from the multi- variant character of the interrelated engineering processes in construction and variety of conditions for work production and construction solutions.

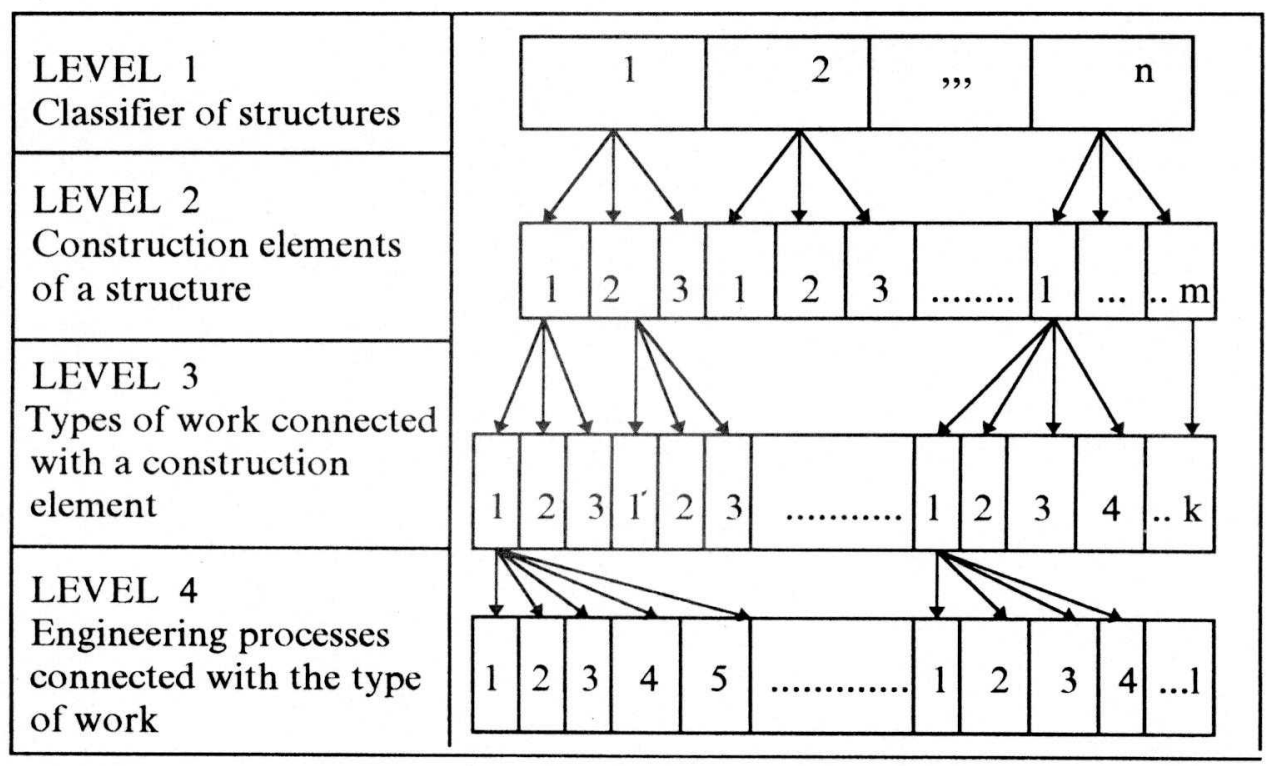

Figure 2 The heirarchical model of resource standard determinants in the AEWPCE complex

There are two parts in the standard base :

1. Standards of resource consumption as measured in natural figures (RESOURCES).

2. Cost of resources (COST). 
The "RESOURCES" part of the base consists of resource standards per single figures used for work measuring with fixed values of resource consumption (machinery , materials, labour and power).

The standard base is created according to hereinbefore described principles for each specific production facility with taking into account the characteristics of technology and available resources. Each resource standard is a special case of engineering process realization. The base of cost standards is presented as cost calculations of machinery maintenance, preparation of finished and semi - finished construction products by auxiliary production facilities and as calculations of transport expenses.

The RESURS program permits consumption calculation of all types of resources for each separate subsystem of construction,i.e. main production facilities, auxiliary production facilities, transport, loading and unloading works, with power consumption being marked out for each subsystem and each type of work. When resources being calculated, the whole chain of transportations, physical,chemical and mechanical transformations of raw materials in the construction line aimed at getting a finished element of a structure used in construction is reproduced.

BLOCK C In this block operative information about the course of work, the condition of machinery, the receipt and consumption of materials at construction projects is accumulated. The block software permits the hourly record of work for each construction machine per a shift and the accumulation of information about falling the machinery out of step, planned and emergency repairs. For making a decision on production process regulation with the appearance of deviation from the schedule an engineer receives information about availability of machinery and material reserves.

Sets of possible solutions with plans of operations in this or that situation help a user to choose the optimal variant of managing influence on construction processes ,to react adequately to a changing situation when realizing a construction program. Information about the real work course at construction projects and machinery functional modes is accumulated in this block during a year, after that it is processed by statistical methods and used for imitation modelling of work schedules (BLOCK A).

\section{EXAMPLES OF PRACTICAL USE}

A management engineer while in practice activities should efficiently analyse different variants of engineering, technological and organization solutions, and choose effective solutions as applied to a specific situation. In the AEWPCE program package the forming of solution variants and their estimating according to different criteria are carried out by the method of Functional -Cost Analysis ( FCA). The FCA objects are:

- schemes of delivery and processing of materials ;

- separate éngineering processes and types of work;

- solutions by the methods of work organization ;

- the choise of machinery sets for work carrying out, etc.

The succesion of AEWPCE user operations at comparison of solution variants by the FCA method in general case can be divided into 3 steps: 
Step 1. Drawing of the Functional - Constructive Model (FCM) of the project being analysed with the description of the succession of substence, power or information transformation.

Step 2 Forming of solution variants on the basis of information of Step1.

Step 3 Estimating and choosing of an effective solution variant.

The analysis and the choise of rational machinery sets for construction of a foundation layer of a road structure made of discrete material will be taken as an easy example of the use of the AEWPCE program package. Fig.3 illustrates FCM fragment of this engineering process. The arrows show the inflows and outflows of materials with brief characteristics of their condition before and after carrying out correspondent work operations : delivery, distribution and compacting of material . Brief descriptions of physical nature of operations are listed below. Representation of the process physical nature as the FCM permits the determination of the fullest set of possible ways of function realization by model elements and the arrangement of structure variants that realize the undertaken task.

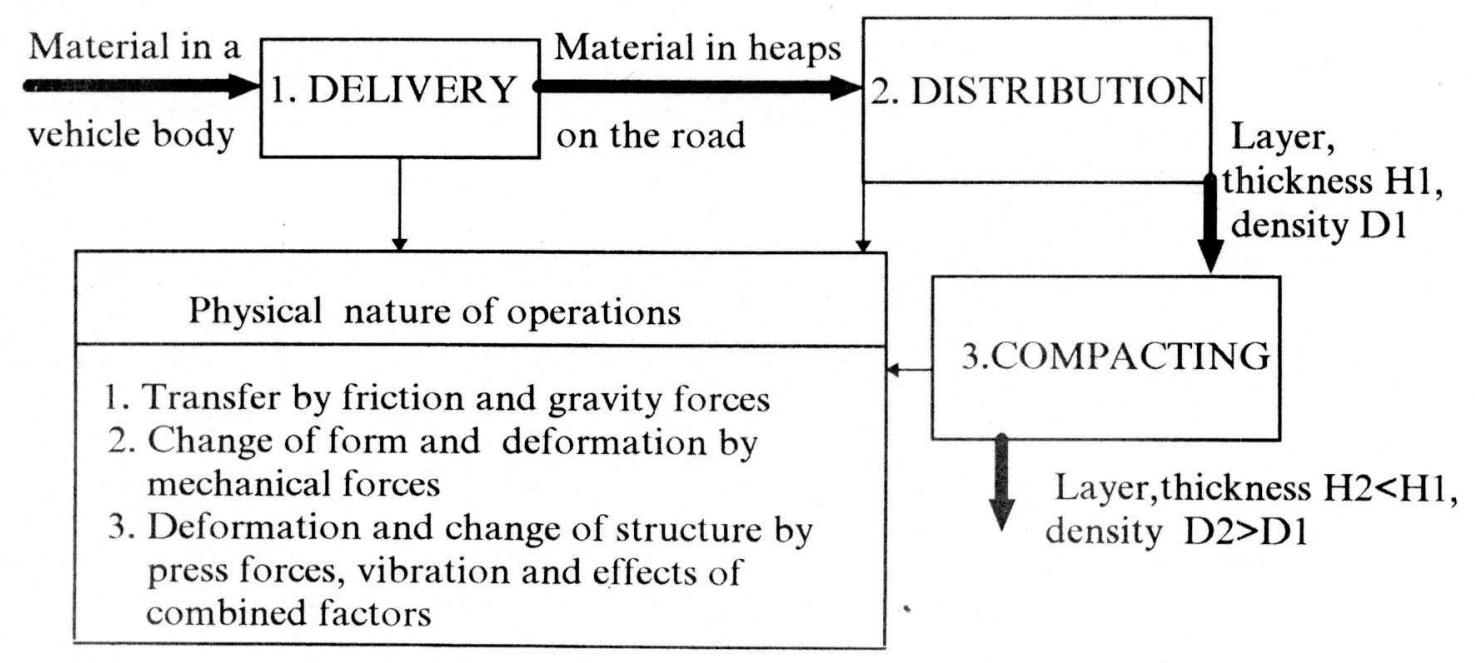

Figure 3 FCM fragment connected with construction of a foundation layer of a road structure

The special -inquiry fund of physical and technical effects as applied to different engineering processes in construction is included into the AEWPCE system . This fund is systimatically filled up and renewed with account of new technologies, machinery and materials appearance. New technology and machinery data in their turn fill up the card-index of resource standards (BLOCK B).

The development of alternative variants is carried out in accordance to the scheme shown in Fig.2. Engineering solution: the set makeup is meant as different combinations of machinery for carrying out different operations. In this example the allternative variants of machinery for fulfilling work operations are proposed ( Level 4--Adopted Technology). The number of variants per each operation depends on the set aims and machinery availability in a specific construction firm. Several variants of 
compacting machinery for carrying out the final work operation can be taken as examples, i.e. smooth-wheel rollers, vibration rollers, combined compacting machinery, pneumatic -tired rollers, ramming plates ,etc.

The alternative variant morphological matrix of work operation fulfillment is reported in Table 1. Each machinery variant is relatively designated by a letter number index $(\mathrm{A} 1, \mathrm{~A} 2, \ldots, \mathrm{B} 1, \ldots \mathrm{C} 1, \mathrm{C} 2, \ldots)$ and in this case is not deciphered . The whole number of possible variants of the set makeup for carrying out three operations is equal to the product of machinery variants per each operation $(4 * 3 * 5=60)$. According the procedure of morphological analysis incompatible variants,if any, must be excluded from the hereinbefore mentioned number of possible variants. A special case of a set makeup is represented as an engineering solution (ES), for example ES:(A1,B3,C2).Estimation of variants according to different criteria is made using the RESURS program complex (Block B). 12 resource standards ( according to the number of machinery variants at level 4) should be created for comparison of proposed variants in the standard base.

Table 1

\begin{tabular}{|l|r|r|r|r|r|r|}
\hline Process / Operations & \multicolumn{5}{|c|}{ A 1 t e r n a t ive v a ri a n t s } \\
\hline $\begin{array}{l}\text { Construction of a foundation } \\
\text { layer of a road structure: }\end{array}$ & 1 & 2 & 3 & 4 & 5 & 6 \\
\hline 1. Delivery & A1 & A2 & A3 & A4 & & \\
\hline 2. Distribution & B1 & B2 & B3 & & & \\
\hline 3. Compacting & C1 & C2 & C3 & C4 & C5 & \\
\hline
\end{tabular}

\section{CONCLUSIONS}

The method of gradual including of new problems solved by a personal computer into a real technology of production management without lost of previously mastered techniques and information constitute the base of research directed to further development of the AEWPCE system. Such approach enables to increase the management functions by using modern modelling methods and to improve information and technical supply, and construction management structure according to logistic principles.

\section{REFERENCES}

1. Mogilevich V.M., Bobrova T.V. Organization of Road Construction Works.M.:Transport, 1990.

2. Solodky A.I.,Karpov B.N. Scheduling and Repairs of Highways.M.:Transport, 1988. 